\title{
DATA FROM ROSSI-ALPHA AND PULSED NEUTRON PROMPT NEUTRON TIME DECAY MEASUREMENTS AT THE OAK RIDGE CRITICAL EXPERIMENTS FACILITY
}

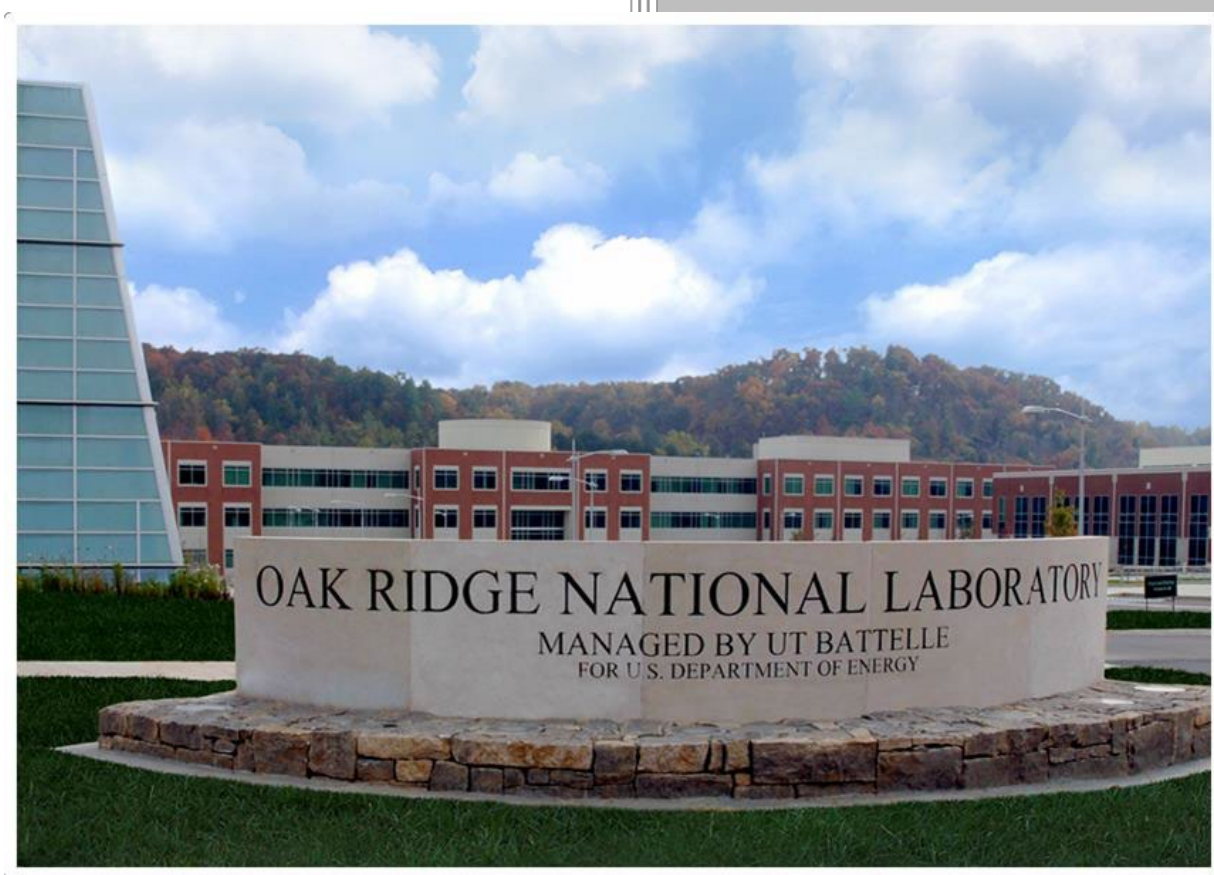

\section{Approved for public release.}

John T. Mihalczo Distribution is unlimited.

April 2019 


\section{DOCUMENT AVAILABILITY}

Reports produced after January 1, 1996, are generally available free via US Department of Energy (DOE) SciTech Connect.

Website www.osti.gov

Reports produced before January 1, 1996, may be purchased by members of the public from the following source:

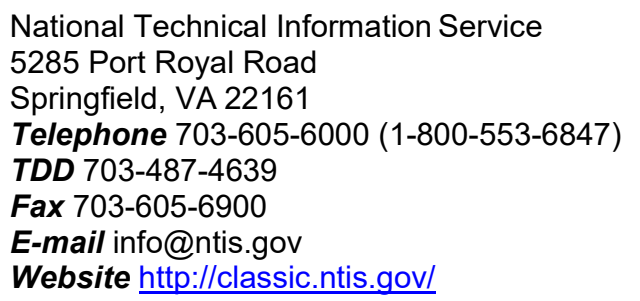

Reports are available to DOE employees, DOE contractors, Energy Technology Data Exchange representatives, and International Nuclear Information System representatives from the following source:

Office of Scientific and Technical Information

PO Box 62

Oak Ridge, TN 37831

Telephone 865-576-8401

Fax 865-576-5728

E-mail reports@osti.gov

Website http://www.osti.gov/contact.html

This report was prepared as an account of work sponsored by an agency of the United States Government. Neither the United States Government nor any agency thereof, nor any of their employees, makes any warranty, express or implied, or assumes any legal liability or responsibility for the accuracy, completeness, or usefulness of any information, apparatus, product, or process disclosed, or represents that its use would not infringe privately owned rights. Reference herein to any specific commercial product, process, or service by trade name, trademark, manufacturer, or otherwise, does not necessarily constitute or imply its endorsement, recommendation, or favoring by the United States Government or any agency thereof. The views and opinions of authors expressed herein do not necessarily state or reflect those of the United States Government or any agency thereof. 
Isotope and Fuel Cycle Technology Division

\title{
DATA FROM ROSSI-ALPHA AND PULSED NEUTRON PROMPT NEUTRON TIME DECAY MEASUREMENTS AT THE OAK RIDGE CRITICAL EXPERIMENTS FACILITY
}

\author{
John T. Mihalczo
}

April 2019

\author{
Prepared by \\ OAK RIDGE NATIONAL LABORATORY \\ Oak Ridge, TN 37831-6283 \\ managed by \\ UT-BATTELLE, LLC \\ for the \\ US DEPARTMENT OF ENERGY \\ under contract DE-AC05-00OR22725
}





\section{CONTENTS}

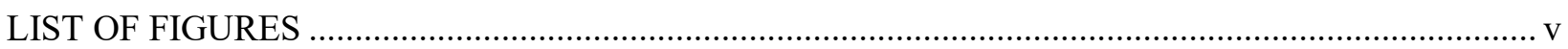

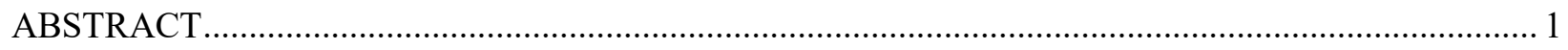

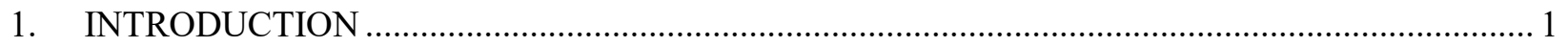

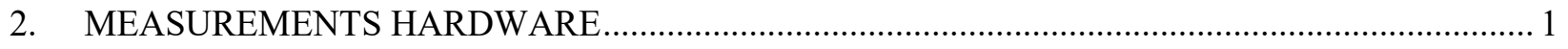

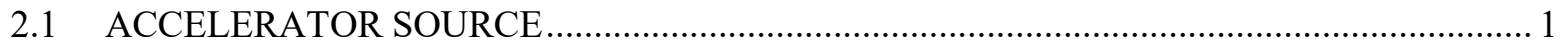

2.2 TIME-TAGGED CALIFORNIUM NEUTRON SOURCES …..................................... 4

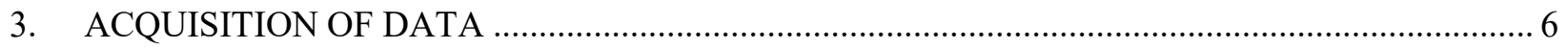

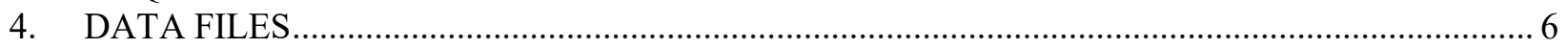

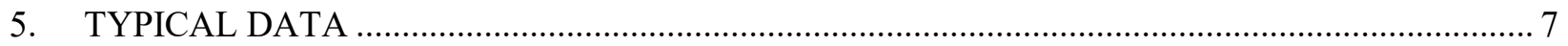

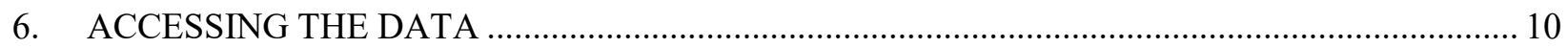

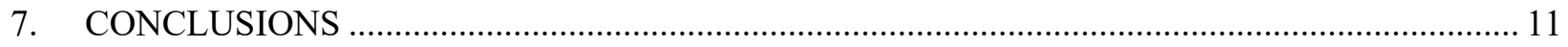

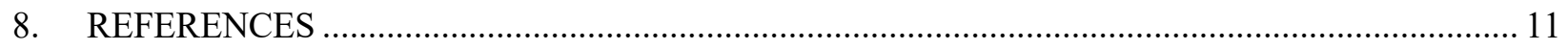





\section{LIST OF FIGURES}

Figure 1. The Cockcroft-Walton Accelerator (target on right and power supplies on wheels in the background)

Figure 2. The Cockcroft-Walton Accelerator with the target near a uranium metal assembly

Figure 3. The initial aluminum ionization chambers (californium deposit was 1 centimeter diameter disc on the platinum foil)

Figure 4. Doubly contained stainless steel ionization chambers...................................................... 5

Figure 5. Time distribution of counts after californium source fission for $17.77 \mathrm{~cm}$ diam. HEU metal cylinders as a function of thickness for a Type II analyzer

Figure 6. Time distribution of counts in a detector near a uranium metal system after californium fission acquired with a Type III analyzer....

Figure 7. Time distribution of counts from a two detector Rossi-alpha measurements for an 11 in. diam, 2.125 in. thick HEU metal cylinder (note that the signal in the second detector has been delayed so both halves of the correlation function).... 10 



\begin{abstract}
This report briefly describes the Rossi-alpha and pulsed neutron prompt neutron time decay measurements performed at the Oak Ridge Critical Experiments Facility. This description includes the measurement equipment, type of data, and how to access the actual data from Records Management Services at Oak Ridge National Laboratory and the Nuclear Criticality Safety Benchmark Program (NCSBEP) of the Idaho National Laboratory. Most of the data were acquired between 1960 and 1975 on weapons-grade enriched uranium metal assemblies. Also included are measurements of the same type performed at Los Alamos National Laboratory by Oak Ridge National Laboratory with the JEZEBEL and FLATTOP criticality assemblies and other plutonium metal parts. The purpose of this report is to allow future mining of the data for publication of additional information that can be used to verify calculational methods and nuclear cross sections. These data can be used to create reactor physics benchmarks for the Nuclear Energy Agency's International Handbook of Evaluated Reactor Physics Experiments. Present calculational methods can be used to directly calculate the measured data. The prompt neutron decay is more neutron spectrum sensitive than other measured quantities, particularly for interacting fissile metal systems where the flight time of neutrons between interacting sections is a large part of the neutron lifetime.
\end{abstract}

\title{
1. INTRODUCTION
}

This report briefly describes Rossi-alpha and pulsed neutron prompt neutron time decay measurements performed at the Oak Ridge Critical Experiments Facility between 1960 and 1975. This description includes the measurement equipment, type of sources, type of detectors, the type of data, and how to access the actual data from Records Management Services at Oak Ridge National Laboratory (ORNL) and the Nuclear Criticality Safety Benchmark Program (NCSBEP) of the Idaho National Laboratory (INL). Also included is how logbooks that contain the measurements can be accessed. Most of the data were acquired between 1960 and 1975 on weapons-grade enriched uranium metal assemblies. The data were originally on 240,000 punch cards and later transferred to digital form for easy access. The fissile material configurations are carefully described in the references and the Nuclear Energy Agency of EURATIOM and the Nuclear Criticality Safety Benchmark Program (NEA/NCSBEP) of INL. This report also provides a list of references in which these measurements were published.

The purpose of this report is to allow future mining of the data for publication of additional information that can be used to verify calculational methods and nuclear cross sections. These data can be used to create reactor physics benchmarks for the Nuclear Energy Agency's International Handbook of Evaluated Reactor Physics Experiments. Present calculational methods can be used to directly calculate the measured data. The prompt neutron decay is more neutron spectrum sensitive than other measured quantities, particularly for interacting fissile metal systems where the flight time of neutrons between interacting sections is a large part of the neutron lifetime.

\section{MEASUREMENTS HARDWARE}

Various neutron sources, plutonium alpha-neutron sources, time-tagged californium sources, and a Cockcroft-Walton accelerator produced repetitive pulses in neutron bursts at a variety of repetition rates.

\subsection{ACCELERATOR SOURCE}

Using a $150 \mathrm{KV}$ Cockcroft-Walton accelerator from Texas Instruments Corp., D-T neutrons (14.1 MeV) were produced by accelerating deuterium into a water-cooled tritiated target. Pulses in the microsecond to millisecond time range were produced by ion source pulsing. For pulses in the 10s of nanoseconds range, the deuterium beam was swept across a narrow slit by radio frequency techniques. This system is shown in Figure 1. Figure 2 shows the target of the accelerator close to a uranium metal assembly. The accelerator is located some distance from the uranium metal assembly to minimize reflection effects. 


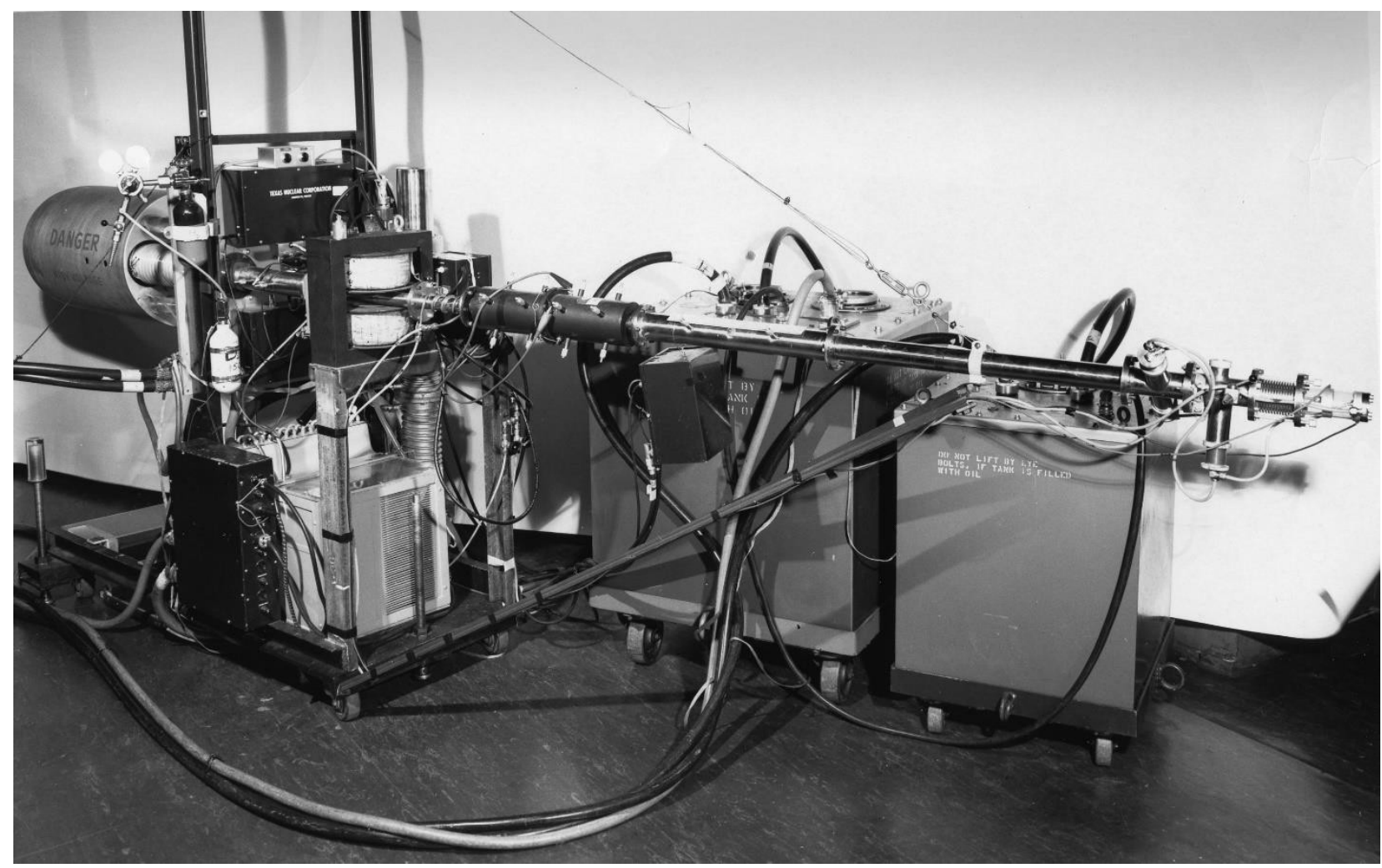

Figure 1. The Cockcroft-Walton Accelerator (target on right and power supplies on wheels in the background). 


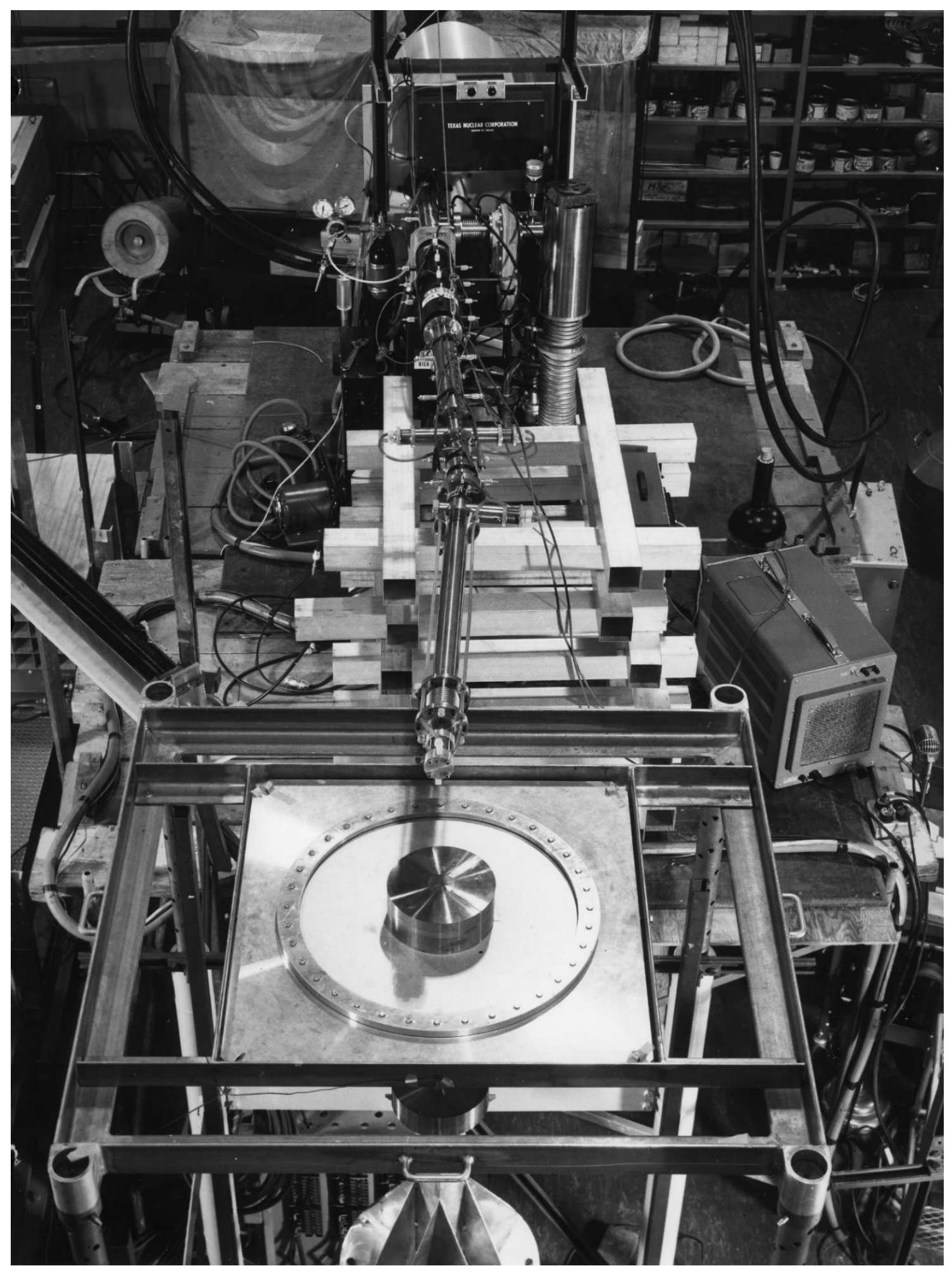

Figure 2. The Cockcroft-Walton Accelerator with the target near a uranium metal assembly. 


\subsection{TIME-TAGGED CALIFORNIUM NEUTRON SOURCES}

In 1968 californium-252 was deposited on one plate of a parallel plate ionization chamber. Ionization of the chamber gas by the fission products produces an electrical pulse that can be used to time the emission of neutrons. The fission products can be easily be distinguished from the ionization pulses produced by alpha emission, which are about 30 times more than fission product pulses. The initial ionization aluminum chambers were single contained. A sketch of this detector is given in Figure 3. In 1988 a doubly contained stainless steel ionization chamber was constructed, as shown in Figure 4. The doubly contained chambers were used in all measurements taken after 1988. In 2001, the doubly contained ionization chambers were redesigned to be hemispherical to minimize the largest alpha pulses by limiting the possible path lengths of the alpha pulses. It failed upon initial use in the laboratory and was never used for measurements with fissile material. It is presently being redesigned.

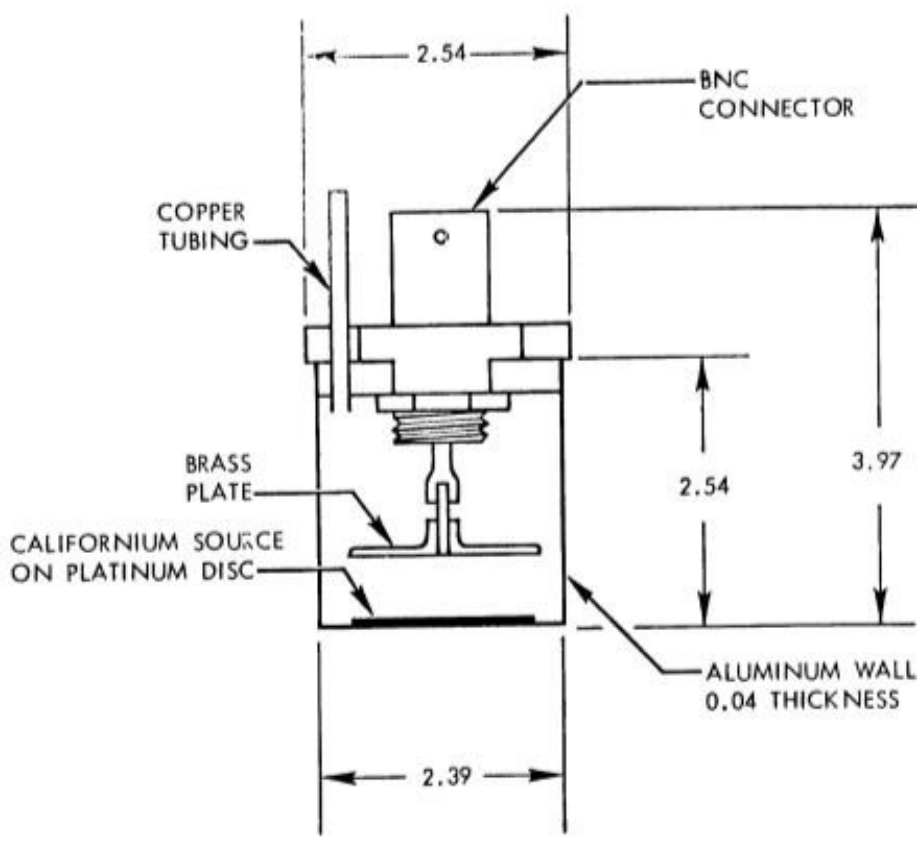

DIMENSIONS IN CM.

Figure 3. The initial aluminum ionization chambers (californium deposit was 1 centimeter diameter disc on the platinum foil). 


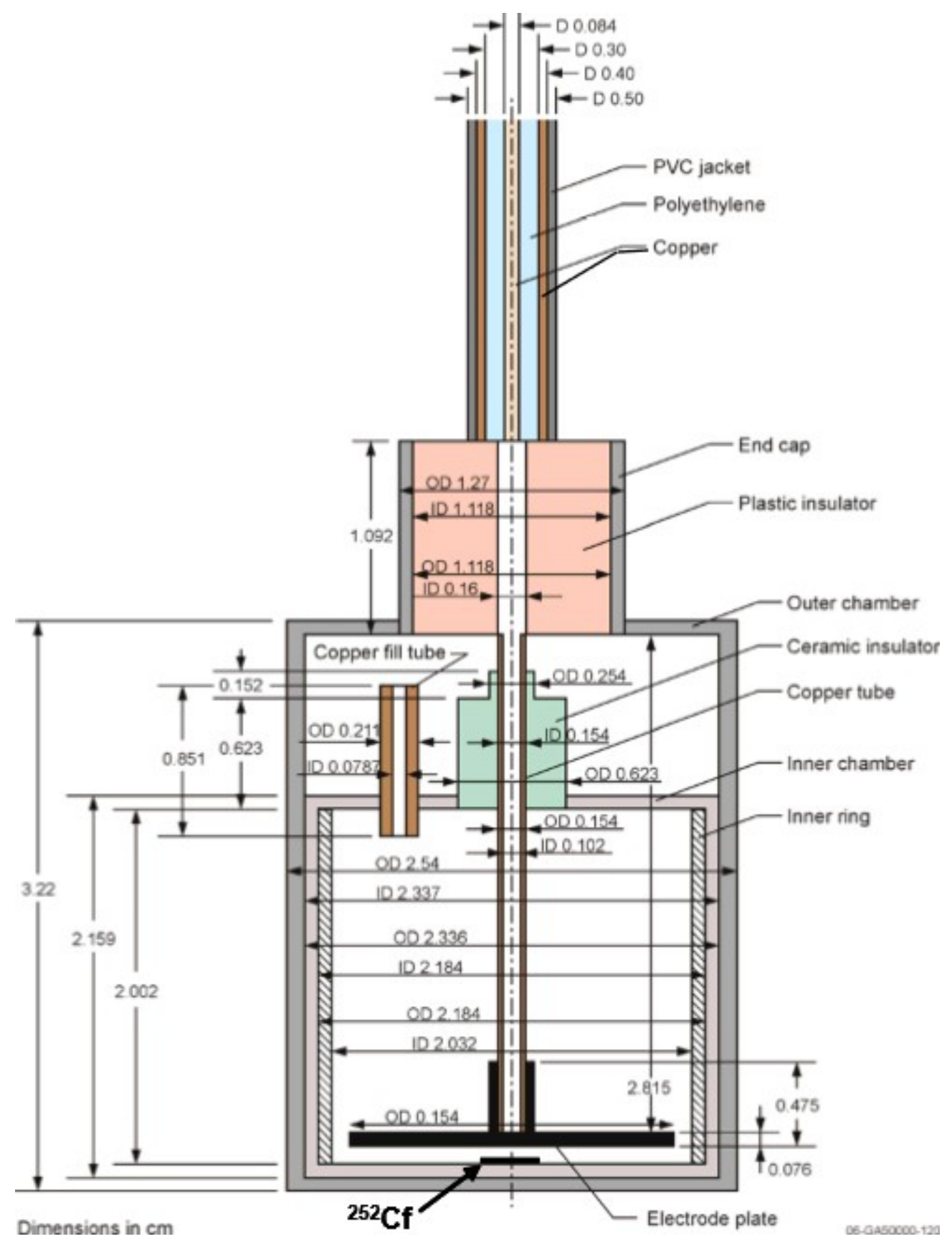

Figure 4. Doubly contained stainless steel ionization chambers.

Other special chambers were built to be located inside fissile metal assemblies such as the Oak Ridge Sphere, JEZEBEL, and FLATTOP, the latter two being Los Alamos National Laboratory (LANL) assemblies in the critical facility. These chambers are described in the references. 


\section{ACQUISITION OF DATA}

The time decay data were acquired using three types of data acquisition systems:

1) A Technical Measurements Corporation (TMC) time analyzer, which was used for longer time decays for nonmetallic fissile systems. This system was used for pulsed neutron measurements with a Cockcroft-Walton $150 \mathrm{kV}$ DT accelerator. This is a Type II analyzer in which one trigger pulse measures subsequent counts as a function of time.

2) A ORTEC Time to Pulse Height Converter (TPHC) whose output was input to a pulse height analyzer. This is a Type III analyzer that for one trigger from the source only accepts one count from the detector and then takes a short time to reset and repeat the process. It was used for two detector Rossi-alpha measurements and pulsed neutron measurements for fissile metallic systems. The common way to use the TPHC is to use the accelerator signal to start the TPHC and the detector signal to stop the TPHC. Because the detector signal is usually lower than the accelerator rate, many of the starts have no stop signal. To increase the useful start rates and to reduce the effects of dead time in pulse neutron measurements, the detector pulse usually started the TPHC and the accelerator pulse stopped the increasing pulse height. In this case the timing pulse from the accelerator indicating that neutrons were produced was had delayed until after the neutron detector pulse. In this case, the direction of the time decay was inverted. In this case the TPHC was triggered only when there was a meaningful detector pulse.

3) A 19 time channel dual-input LANL designed and built shift register that accepts multiple sequential triggers and multiple sequential detector events. This system could be used with one input or two. It measured the time distribution of counts in one detector with respect to a previous count in the same detector (singles mode-single detector Rossi-alpha) or another detector (doubles mode-two-detector Rossi-alpha or pulsed neutron measurement with the pulse associated with the source into channel 1 and the detector pulse into channel 2). This system also measured the singles, doubles, triples, quadruples, and quintuples that occurred in the total time interval of the measurement (19 channels time the time width of each channel). These multiplicities were recorded in the East cell logbooks. It was used for fissile metallic systems at ORNL and LANL. At LANL both highly enriched uranium metal (HEU) and plutonium metal measurements were performed.

In the 1990s a Nuclear Material Identification System (NMIS) processor was developed. This multichannel $1 \mathrm{GHz}$ shift register was a Type I analyzer that accepted all triggers and detector pulses consistent within a few nanoseconds $\left(10^{-9}\right.$ seconds) of dead time determined by the width of the narrowest detector pulses. The time interval of a measurement varied from $\geq 1$ nanosecond. The original fivechannel NMIS processor was modified to 10 channels that recognize the detector pulse widths and has been used to process up to 60 detector inputs by sorting the times of arrival of the pulses according to pulse width.

\section{DATA FILES}

The data files consist of a title card that contains a description of the configuration, date of the measurement, channel width, and logbook page where the measurement was recorded. All measurements at ORNL were in the East cell of the Oak Ridge Critical Experiments Facility (ORCEF). The date of the measurements can signify in which East cell logbook the measurement was recorded since all entries in East cell logbooks were sequential. A typical title of the files is as follows: 


\section{3-15-72 G 19 D 9213 SPHERE DC CF59E200 HE3 .1E-6 P-144}

This title gives a date of 3-15-72 first. The date can be associated with a logbook since there were no logbooks with entries on the same date.

G denotes run $\mathrm{G}$ on the above date

19 denotes the number of time channels

D denotes double or two detector measurement where the time distribution of count in the detector in channel 2 is measured with respect to a previous count in detector 1 . If a $\mathrm{S}$ appears here, it is a single detector Rossi-alpha measurement where the time distribution of counts in a detector is measured with respect to a previous count in the same detector.

19 denotes the number of time channels and will always say 19 for the LANL shift register.

$\mathbf{9 2 1 3}$ is the building number for the critical facility at Oak Ridge.

Sphere denotes the uranium metal sphere—so 9213 SPHERE is the assembly.

DC denotes a measurement at delayed critical.

CF59 indicated time-tagged californium source number 59 and will always be the input to channel 1 .

HE3 indicated the type of detector signals in channel 2.

0.1E-6 indicates the time channel width of 0.1 microseconds.

P-144 indicates the page number in the logbook. The logbook for the East cell can be determined from the date since logbook entries were sequential.

The californium signal is input to channel 1 of the LANL shift register, the HE3 detector signal is input to channel, and the time distribution of count in the detector is measured with respect to a previous count in the time-tagged californium source.

Logbooks in the East cell of ORCEF are sequential with dates. Look at the list of logbooks and find one for the date 3-15-72 and look on page 143 of the logbook for more information on the measurement.

\section{TYPICAL DATA}

Typical data for a time correlation measurement between a detector and a californium source for HEU uranium metal subcritical cylinders are given in Figure 5 with the source in the center of flat surface and detector adjacent to the radial surface in $1 / 4$ in. thick lead. The data in Figure 6 were acquired with a Type III analyzer in which the rigger was a time-tagged californium source and the time distribution of count with respect to californium fission was recorded. The signal from the detector was delayed so that the buildup of the distribution could also be measured. Sometime after, the peak elapsed before exponential decay occurred. The data in Figure 7 are for 7 in. diam. enriched uranium metal cylinders of various heights. 


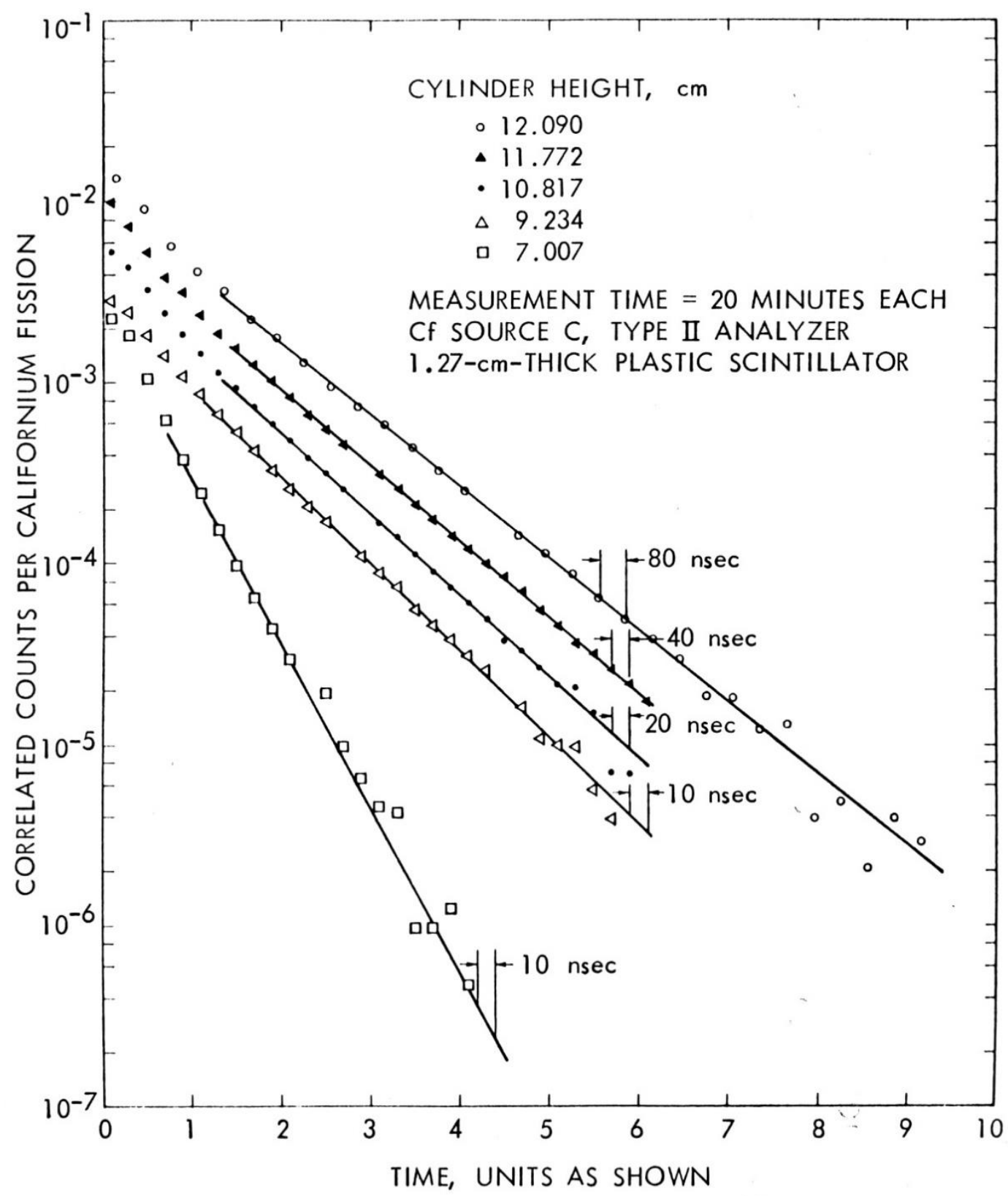

Figure 5. Time distribution of counts after californium source fission for $17.77 \mathrm{~cm}$ diam. HEU metal cylinders as a function of thickness for a Type II analyzer. 


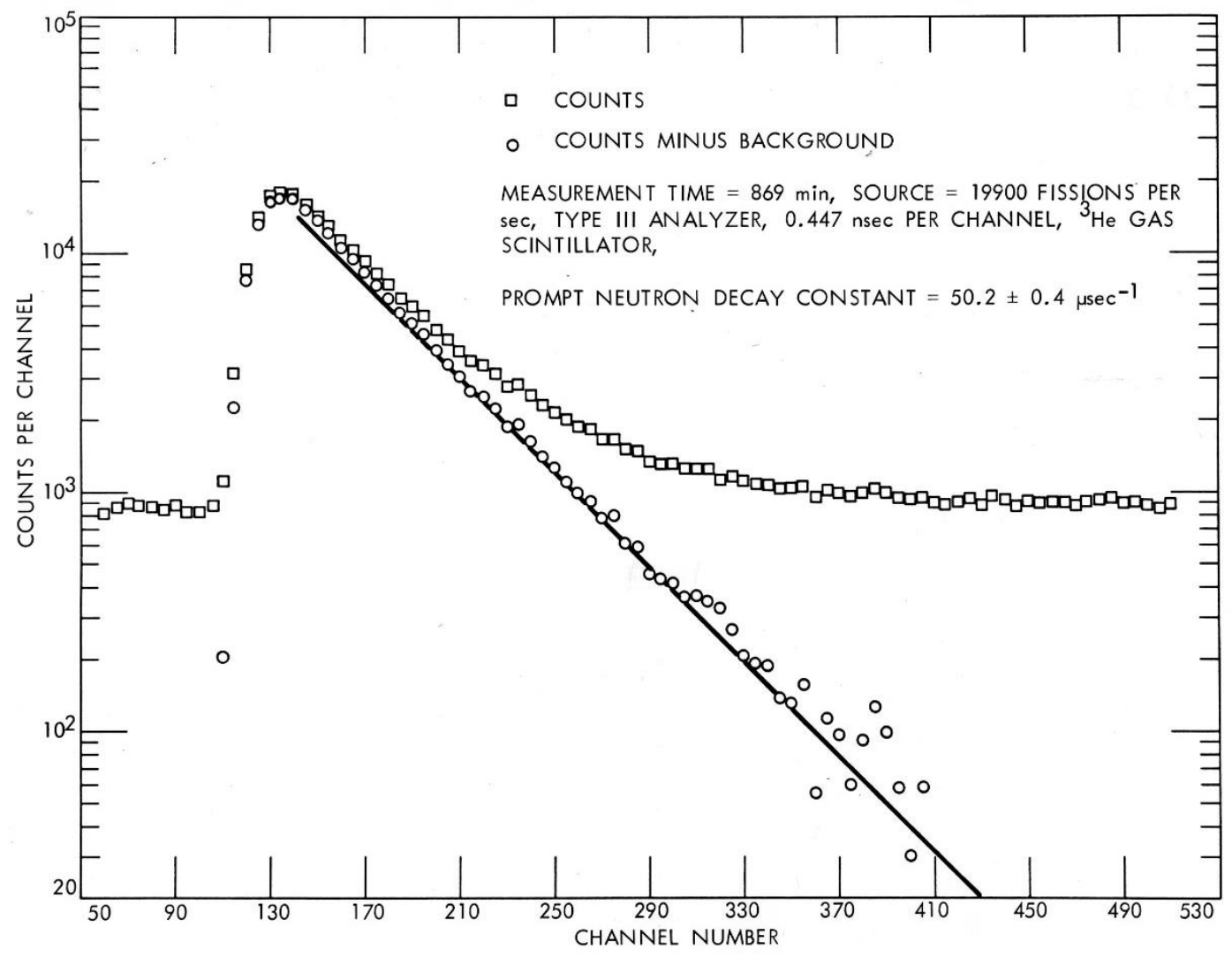

Figure 6. Time distribution of counts in a detector near a uranium metal system after californium fission acquired with a Type III analyzer. 


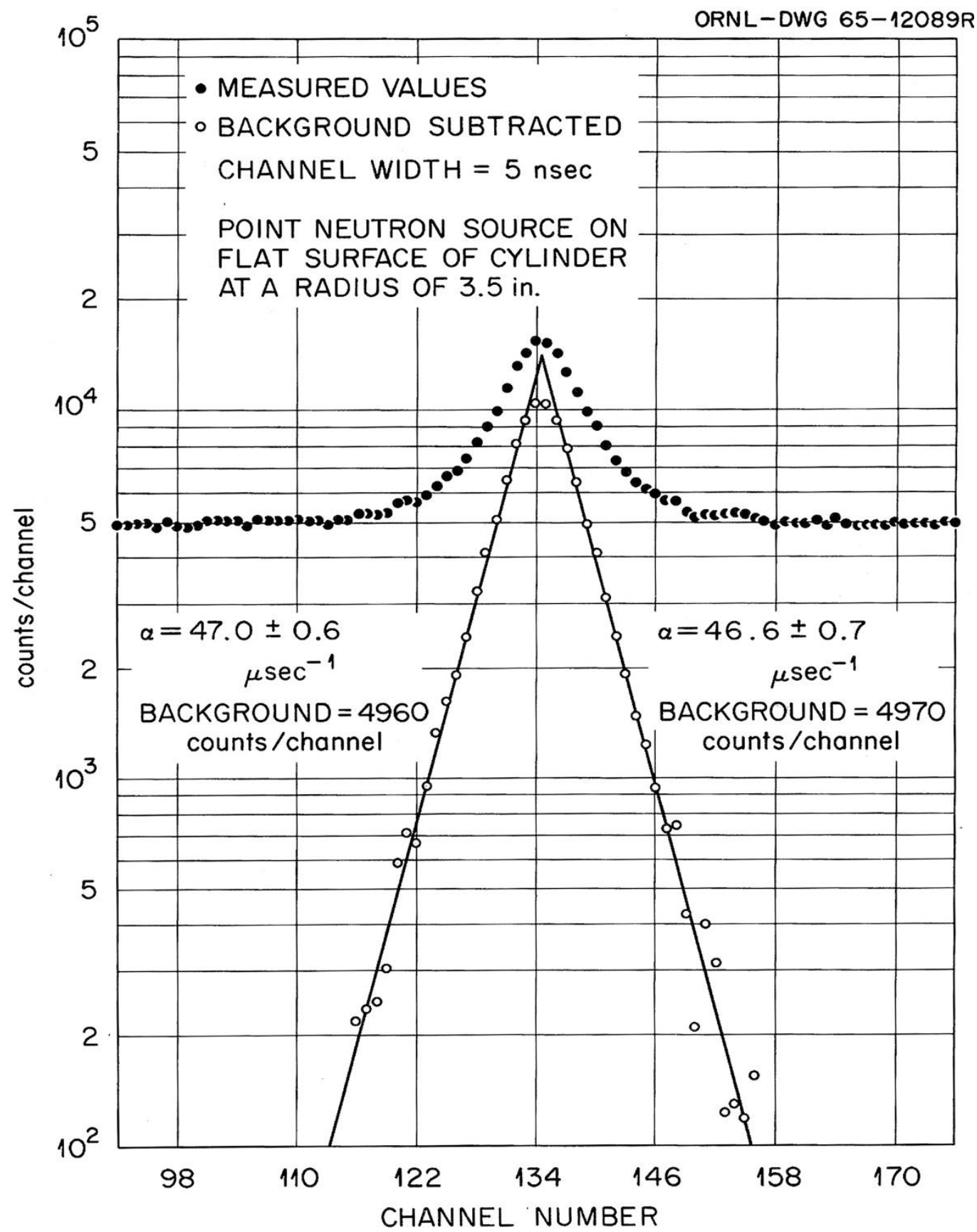

Figure 7. Time distribution of counts from a two detector Rossi-alpha measurements for an 11 in. diam, 2.125 in. thick HEU metal cylinder (note that the signal in the second detector has been delayed so both halves of the correlation function).

\section{ACCESSING THE DATA}

The logbooks can be access by contacting John Bess of INL (208-526-4375, 208-206-1286, or at john.bess@inl.gov).

Access to the data can be obtained by contacting Missy Baird, Records Management Services, ORNL (865-574-6753 or bairdmh@ornl.gov). The data can also be obtained using the following link. 


\section{CONCLUSIONS}

This report briefly describes Rossi-alpha and pulsed neutron prompt neutron time decay measurements performed at the Oak Ridge Critical Experiments Facility. The description also includes measurement equipment, type of data, and how to access the actual data from Records Management Services of ORNL and the Nuclear Criticality Safety Benchmark Program (NCSBEP) of INL. Most of the data was acquired between 1960 and 1975 on weapons-grade enriched uranium metal assemblies. It also includes measurements of the same type performed at LANL by ORNL. These data can be calculated directly by present calculational methods and thus can be used to verify calculation methods and cross sections. These data can be used to create reactor physics benchmarks for the Nuclear Energy Agency's International Handbook of Evaluated Reactor Physics Experiments.

\section{REFERENCES}

This list of references gives the publications in which the pulsed neutron and Rossi-alpha measurements are described. They are divided into three categories: journal papers, reports, and presentations at scientific meetings. No all publications are included.

Joufnalt.Pareas, J. T. Mihalczo, and R. C. Robinson, "Prompt Neutron Decay Constants at Delayed Criticality for the Oak Ridge Research Reactor with 20 and 93 wt. \% 235U Enriched Fuel," Annals of Nuclear Energy 24 (1), 21-31 (1997)

2. J. T. Mihalczo, "Prompt Alpha and Reactivity Measurements on Fast Metal Assemblies," Nucl. Energy, 1, 1-26 (1977)

3. J. T. Mihalczo, "Time Domain Noise Measurements for Fast Metal Assemblies with 252Cf," Ann. Nucl. Energy, 2, 161-75 (1975)

4. J. T. Mihalczo, "The Use of Californium-252 as a Randomly Pulsed Neutron Source for Prompt Neutron Decay Measurements," Nucl. Sci. Eng., 53, 393-414 (1974)

5. J. T. Mihalczo, "The Use of 252Cf as a Randomly Pulsed Neutron Source for Prompt NeutronDecay Measurements," Nucl. Sci. Eng., 41, 296 (1970)

6. J. T. Mihalczo, "Prompt Neutron Decay and Reactivity Measurements in Subcritical Uranium Metal Cylinders," Nucl. Sci. Eng., 32, 292 (1968)

\section{Reports}

1. J. T. Mihalczo, J. J. Henkel, M. C. Wright, D. E. Archer, J. A. Mullens, Subcriticality Measurements with HEU (93.2) Metal Annular Storage Castings, Oak Ridge National Laboratory, ORNL/TM2007/134 (2007) [OSTI \#988200]

2. J. T. Mihalczo, D. E. Archer, M. C. Wright, J. A. Mullens, Pulsed Neutron Measurements with a DT Neutron Generator for an Annular HEU Uranium Metal Casting, ORNL/TM-2007/092 (9/1/2007)

3. J. T. Mihalczo, Prompt Neutron Decay in Plutonium Metal Using 252Cf as a Randomly Pulsed Neutron Source, Y/DR-111, Union Carbide Corp. Nuclear Division, Oak Ridge Y-12 Plant (August 1973) [OSTI \#4686870]

4. J. T. Mihalczo, The Use of 252Cf as a Randomly Pulsed Neutron Source for Prompt Neutron Decay Measurements, Y/DR-41, Union Carbide Corp. Nuclear Division, Oak Ridge Y-12 Plant (January 1971). 
5. J. T. Mihalczo, Prompt Neutron Decay and Reactivity Measurements in Subcritical Uranium Metal Cylinders, ORNL/TM-1736, Union Carbide Corp. Nuclear Division, Oak Ridge National Laboratory (1968) [OSTI \#4556018]

6. J. T. Mihalczo, Prompt Neutron Decay in a Two-Component Enriched Uranium Metal Critical Assembly, ORNL/TM-470, Union Carbide Corp. Nuclear Division, Oak Ridge National Laboratory (1963) [OSTI \#4728701]

\section{Papers presented at a scientific meeting}

1. L. D. Phillips et al., "Hemispherical ${ }^{252}$ Cf Fission Chambers for Better Discrimination of Alpha Particle Decay Products," Inst. of Nuclear Materials Management, Orlando, FL USA, INMM, 06/23/2002-06/27/2002. (July 2002)

2. T. E. Valentine, Perez, J. A. Mullens, J. T. Mihalczo, "Passive Multiplicity Counting with NMIS for $\mathrm{Pu}$," presentation at Inst. of Nuclear Materials Management, Phoenix AZ, July 25-29, 1999 (July 1999)

3. J. T. Mihalczo, "Prompt neutron decay for loosely coupled delayed critical 38.1-cm.-diam uranium (93.2) metal cylinders," Transactions of the American Nuclear Society, V75, Winter Meeting of the American Nuclear Society (ANS) and the European Nuclear Society (ENS) Washington, DC (December 1997) [OSTI \#426526]

4. J. T. Mihalczo, "Prompt Neutron Decay for Very Loosely Coupled Delayed Critical 38.1-cm-diam Uranium (93.2) Metal Cylinders," Trans. Amer. Nucl. Soc., 75, 350-351 (1996)

5. J. T. Mihalczo, "Prompt Neutron Decay Constants for a Delayed Critical Configuration of the Oak Ridge Unreflected and Unmoderated Uranium Metal Sphere," PHYSOR '96 Conference, Mito, Japan (September 1996) [OSTI \#378175]

6. J. T. Mihalczo, "Interacting Delayed Critical 38.1-cm-diam Uranium (93.2) Metal Cylinders At Large Distance," American Nuclear Society Annual Meeting, Reno, Nevada, Trans. Amer. Nucl. Soc., 74, 195 (1996).

7. G. E. Ragan and J. T. Mihalczo, "Prompt Neutron Decay Constant for the Oak Ridge Research Reactor with 20 wt. \% 235U Enriched Fuel," Proceedings of the America Nuclear Society Topical Meeting on Reactor Physics and Safety, Saratoga, New York, September 17, 1986, NUREG/CP-0080 Vol. 2, 1139-44 (September 1986)

8. J. T. Mihalczo, "Prompt Alpha and Reactivity Measurements on Fast Metal Assemblies," Proceedings of U.S./Japan Seminar on Fast Pulse Reactors, University of Tokyo, Tokyo, Japan, (January 1976).

9. J. T. Mihalczo, "Prompt Neutron Decay in Plutonium Metal Using ${ }^{252} \mathrm{Cf}$ as a Randomly Pulsed Neutron Source," Trans. Am. Nucl. Soc. 15, 471 (1972)

10. J. T. Mihalczo, "Prompt Neutron Decay in Delayed Critical Assemblies of Three Interacting Cores," Trans. Am. Nucl. Soc. 10, 242 (1967) [OSTI \#4273797]

11. J. T. Mihalczo, "Rossi-Alpha and Pulsed Neutron Measurements," National Topical Meeting of American Nuclear Society on Coupled Reactor Kinetics at Texas A\&M, 484-505 (January 1967).

12. J. T. Mihalczo, "Prompt Neutron Time Behavior in Delayed Critical Coupled Uranium Metal Cylinders," Proceedings of the International Conference on Fast Critical Experiments and Their Analysis, ANL-7320, 237-41 (October 1966)

13. J. T. Mihalczo, "Prompt Neutron Decay in Delayed Critical Assemblies of Three Interacting Cores," Trans. Am. Nucl. Soc. 10, 242 (1967) [OSTI \#4273797] 
14. J. T. Mihalczo, "Rossi-Alpha and Pulsed Neutron Measurements," National Topical Meeting of American Nuclear Society on Coupled Reactor Kinetics at Texas A\&M, 484-505 (January 1967)

15. J. T. Mihalczo, "Prompt Neutron Time Behavior in Delayed Critical Coupled Uranium Metal Cylinders," Proceedings of the International Conference on Fast Critical Experiments and Their Analysis, ANL-7320, 237-41 (October 1966)

16. J. T. Mihalczo, "Rossi-Alpha Measurements in Subcritical Uranium-Metal Cylinders," Trans. Am. Nucl. Soc. 9, 175 (1966) [OSTI \#4522016]

17. J. T. Mihalczo, "Prompt-Neutron Decay in a Two-Component Enriched Uranium Metal Critical Assembly," Trans. Am. Nucl. Soc. 6, 60 (1963)

18. J. T. Mihalczo, "Prompt Neutron Lifetime in Hydrogen-Moderated 3\% ${ }^{235}$ U Enriched Uranium Critical Assemblies," Trans. Am. Nucl. Soc. 5, 387 (1962)

19. J. T. Mihalczo, "Heterogeneous Critical Assemblies of Enriched Uranium Metal Plates and Polyethylene," American Nuclear Society 1995 Winter Meeting, San Francisco, California, Trans. Amer. Nucl. Soc., 73, 219-220 (1995) [OSTI \#411655] 
